\title{
Chorioallantoic membranes of embryonated chicken eggs as an alternative system for isolation of equine influenza virus
}

\author{
Ilona Marcelina Gora, Malgorzata Kwasnik, Jan Franciszek Zmudzinski and Wojciech Rozek
}

\begin{abstract}
Background: Influenza virus isolation in embryonated chicken eggs (ECEs) is not applicable for rapid diagnosis, however it allows the recovery and propagation of the viable virus. A low number of infectious virus particles in the swabs, poor quality of samples or individual strain properties can lead to difficulties during the virus isolation process. We propose to utilize chorioallantoic membranes (CAM) of ECEs with the assistance of real-time RT PCR to facilitate equine influenza virus isolation.
\end{abstract}

Methods: Real-time RT PCR was used to detect influenza virus genetic material in amniotic/allantoic fluids (AF) and CAM of ECEs. Haemagglutination assay was used for AF. We used highly diluted virus as a substitute of clinical specimen for ECEs inoculation.

Results: Our study demonstrated that real-time RT PCR testing of CAM homogenates was more useful than testing of AF for EIV detection in ECEs. Positive results from CAM allowed to select the embryos from those with haemagglutination assay (HA) - and real-time RT PCR-negative AF for further passages. Using homogenates of CAM for subsequent passages, we finally obtained HA-positive AF, which confirmed virus replication.

Conclusion: We postulate that real-time RT PCR testing of CAM homogenates and their subsequent passages may facilitate the isolation of equine influenza viruses.

Keywords: Influenza virus, Virus isolation, Chorioallantoic membranes

Equine influenza has been diagnosed both in vaccinated and unvaccinated horses, however the infection was not always confirmed by virus isolation [1]. Detection of equine influenza virus (EIV) directly from nasopharyngeal swabs of horses is usually performed using immunoenzymatic antigen detection methods (e.g. ELISA, rapid antigen detection tests) or viral nucleic acid amplification [2, 3]. Real-time RT PCR (rtRT PCR) is the most sensitive assay for EIV detection currently available [4,5]. Virus isolation in embryonated chicken eggs (ECEs) or Madin-Darby canine kidney cells is not required for rapid diagnosis, however it allows the recovery and propagation of the viable viral strains, which is essential for virus characterization.

\footnotetext{
* Correspondence: wojciech.rozek@piwet.pulawy.pl

Department of Virology, National Veterinary Research Institute, Partyzantow 57, 24100 Pulawy, Poland
}

Traditionally, ECEs have been preferred for isolation of EIV and some authors proved that ECEs were more effective for virus isolation than cell cultures [6]. According to the OIE Terrestrial Manual, amniotic/allantoic fluids (AF) are tested by haemagglutination assay (HA) and passaged into new eggs. If the HA titre is 16 or more, isolates are characterized immediately. If the HA titre is low or no haemagglutination activity is found, aliquots of AF are pooled and further passaged in ECEs. If virus is not recovered by the fifth passage, further passages are not likely to be successful [7]. To recover some influenza virus strains from clinical material, more sensitive assays for virus detection in ECEs are needed. Additionally to $\mathrm{HA}$ of $\mathrm{AF}$, we examined chorioallantoic membranes (CAM) and AF by rtRT PCR for the detection of $\mathrm{M}$ gene of influenza A virus. CAM homogenates from ECEs inoculated with highly-diluted EIV were 
used for subsequent passages until virus was detectable in AF by HA.

EIV strain A/equine/Pulawy/2008 (H3N8) having titre $10^{7.1} \mathrm{EID} 50 / \mathrm{ml}$ (3rd passage in ECEs) was serially diluted from $10^{-1}$ to $10^{-8}$. Six 9-day-old ECEs were inoculated with $0.2 \mathrm{ml}$ of each dilution into the allantoic sac. After $72 \mathrm{~h}$ incubation at $37{ }^{\circ} \mathrm{C}$ ECEs were cooled down to $4{ }^{\circ} \mathrm{C}$. After AF have been collected, the body of embryo and yolk membrane were removed from the egg shell. CAM were separated out with sterile tweezers. Each CAM was rinsed in cold PBS, weighted, frozen in $-70^{\circ} \mathrm{C}$ and defrosted. To each CAM three volumes $(v / w)$ of PBS were added and samples were sonicated $(30 \mathrm{~s}, 130 \mathrm{~W})$. Haemagglutination titre was determined for AF. RNA was extracted from AF and CAM homogenates using TRI Reagent ${ }^{\circ}$ (Sigma-Aldrich, St. Louis, USA) as described by Chomczynski and Sacchi [8]. The TaqMan rtRT PCR was performed using a QuantiTect Probe RT-PCR kit (Qiagen, Hilden, Germany) on the 7500 Fast real-time PCR system (Applied Biosystems, Foster City, USA) according to the protocol recommended by WHO [9]. Primers and the probe used in this study targeted the conservative influenza virus $M$ gene: InfA Forward 5'-GACCRATCCTGTCACCTCTGAC-3'; InfA Reverse 5'-AGGGCATTYTGGACAAAKCGTCTA3'; InfA Probe1 5'-FAM TGC AGT CCT CGC TCA CTG GGC ACG -BHQ1-3'. The reaction was conducted in a total volume of $25 \mu \mathrm{l}$ containing $0.4 \mu \mathrm{M}$ of each primer, $0.12 \mu \mathrm{M}$ of probe and $2 \mu \mathrm{l}$ of viral RNA. Reaction conditions were as follows: one cycle at $45^{\circ} \mathrm{C}$ for $10 \mathrm{~min}$, followed by $10 \mathrm{~min}$ at $95^{\circ} \mathrm{C}$, and 40 cycles of $15 \mathrm{~s}$ at $95^{\circ} \mathrm{C}$ and $45 \mathrm{~s}$ at $60{ }^{\circ} \mathrm{C}$. Statistical analysis was done based on six replicates of both AF and CAM for each dilution. Mann - Whitney $U$ test [10] was used to describe differences in $C_{t}$ values between CAM and AF.

A haemagglutination assay was used for AF from ECEs inoculated with $10^{-1}$ to $10^{-8}$. HA titers 64 and above were obtained for the dilution range $10^{-1}$ to $10^{-5}$. For $10^{-6}$ dilution $50 \%$ of ECEs were HA positive and the highest standard deviation (SD) of Ct was observed (Table 1). Using higher viral dilutions we obtained ECEs with no HA titres. For this group we tested AF and CAM with rtRT PCR. The mean $C_{t}$ values were lower for CAM than for AF in dilutions $10^{-5}$ to $10^{-8}$. Positive results in rtRT PCR $\left(C_{t}<38\right)$ were obtained for ECEs inoculated by $10^{-6}$ EIV dilution for AF and by $10^{-8}$ (mean $C_{t}=33.15$ ) for CAM homogenates. The $\mathrm{Ct} 38$ threshold for positive results was based on O.I.E. protocol recommendations [9]. AF from infected ECEs (HA 256) and AF from uninfected ECEs (HA negative) were used as positive and negative controls, respectively. Ct values in the range from 14.1 to 15 for positive and $>38.9$ for negative controls were obtained. Beta actin gene was used as internal control of rt RT PCR and mean Ct value 30.94 and 19.15 were obtained for AF and CAM, respectively. There was no correlation between
Table 1 Real-time RT PCR of amniotic/allantoic fluids (AF) and chorioallantoic membranes (CAM) from embryonated chicken eggs inoculated with A/equine/Pulawy/2008

\begin{tabular}{|c|c|c|c|c|c|c|c|c|}
\hline \multirow{2}{*}{$\begin{array}{l}\text { Dilution } \\
\text { Sample }\end{array}$} & \multicolumn{2}{|l|}{$10^{-5}$} & \multicolumn{2}{|l|}{$10^{-6}$} & \multicolumn{2}{|c|}{$10^{-7}$} & \multicolumn{2}{|l|}{$10^{-8}$} \\
\hline & $\mathrm{AF}$ & CAM & AF & CAM & $\mathrm{AF}$ & CAM & $\mathrm{AF}$ & CAM \\
\hline \multirow[t]{6}{*}{ Ct $(n=6)$} & $19.3^{\mathrm{a}}$ & 11.3 & 36 & 27.4 & 40 & 32.1 & 40 & 29.7 \\
\hline & $19.3^{b}$ & 12.3 & $18.4^{\mathrm{a}}$ & 8.5 & 40 & 32 & 40 & 34.6 \\
\hline & $19.4^{\mathrm{a}}$ & 12.2 & $19^{\mathrm{a}}$ & 13.3 & 40 & 32.7 & 40 & 33.1 \\
\hline & $14.5^{\mathrm{b}}$ & 12.6 & 35.6 & 24.9 & 40 & 30.1 & 40 & 34.9 \\
\hline & $16.3^{b}$ & 12.4 & $18.2^{\mathrm{a}}$ & 8.9 & 40 & 33.9 & 38.9 & 34.2 \\
\hline & $19.5^{\mathrm{a}}$ & 11.5 & 35.9 & 24.3 & 40 & 30.8 & 40 & 32.4 \\
\hline Mean & 18.05 & 12.05 & 27.18 & 17.88 & 40 & 31.93 & 39.81 & 33.15 \\
\hline SD & 2.1 & 0.5 & 9.5 & 8.6 & 0 & 1.4 & 0.4 & 1.9 \\
\hline$p$ & & 0.0050 & & 0.1735 & & 0.0028 & & 0.0037 \\
\hline
\end{tabular}

Ct values for $\mathrm{M}$ and beta actin genes. Results are presented in supplementary materials ("Additional file 1"). Our study showed that rtRT PCR testing of CAM homogenates was more helpful than rtRT PCR of AF for EIV detection in ECEs. Inoculation of low doses of virus $\left(10^{-7}\right.$ and $10^{-8}$ dilutions) resulted in negative $\mathrm{HA}$ titre as well as negative rtRT PCR of AF, while results of rtRT PCR for CAM showed the presence of the viral genetic material. Detection of EIV genetic material in ECEs is not the proof of the presence of viable virus, however, it may indicate the potential virus source.

In the second part of the experiment, passages of pooled CAM homogenates and AF harvested from ECEs inoculated with the virus A/equine/Pulawy/2008 diluted from $10^{-6}$ to $10^{-8}$ were performed. The first passage was done with ECEs, which AF were previously confirmed negative in HA. Inoculation with the highest dilution $\left(10^{-8}\right)$ was triplicated. We tested if subsequent passages of CAM homogenates would result in HA-positive AF. Positive HA results for AF were obtained in the first passage of CAM homogenates derived from ECEs inoculated with $10^{-6}$ virus dilution. For more diluted inoculum, positive HA titres of AF were obtained in the second or third passages of $10^{-7}$ and $10^{-8}$ dilutions, respectively (Table 2). Passages of AF resulted in negative HA $(\mathrm{HA}<4)$ of AF by the third passage (except for one sample with HA 8 in the third passage of AF derived from embryo inoculated with $10^{-7}$ dilution). AF samples were tested also by rtRT PCR for $M$ gene and Ct values below 38 were obtained in all cases (data included in "Additional file 2").

A low number of infectious viral particles in the swabs, poor quality of samples or individual strain properties can lead to difficulties in the influenza virus isolation. 
Table 2 HA titres of amniotic/allantoic fluids (AF) in three consecutive passages of AF or chorioallantoic membranes (CAM) homogenates

\begin{tabular}{|c|c|c|c|c|c|c|c|c|c|c|}
\hline \multicolumn{6}{|l|}{ CAM } & \multicolumn{5}{|l|}{$\mathrm{AF}$} \\
\hline Dilution & $10^{-6}$ & $10^{-7}$ & $10^{-8}$ & $10^{-8}$ & $10^{-8}$ & $10^{-6}$ & $10^{-7}$ & $10^{-8}$ & $10^{-8}$ & $10^{-8}$ \\
\hline 1st passage & 128 & $<4$ & $<4$ & $<4$ & $<4$ & $<4$ & $<4$ & $<4$ & $<4$ & $<4$ \\
\hline \multirow[t]{2}{*}{$(n=3)$} & 128 & $<4$ & $<4$ & $<4$ & $<4$ & $<4$ & $<4$ & $<4$ & $<4$ & $<4$ \\
\hline & 256 & $<4$ & $<4$ & $<4$ & $<4$ & $<4$ & $<4$ & $<4$ & $<4$ & $<4$ \\
\hline 2nd passage & & 128 & $<4$ & $<4$ & $<4$ & $<4$ & $<4$ & $<4$ & $<4$ & $<4$ \\
\hline \multirow[t]{4}{*}{$(n=5)$} & & $<4$ & $<4$ & $<4$ & $<4$ & $<4$ & $<4$ & $<4$ & $<4$ & $<4$ \\
\hline & & 256 & $<4$ & $<4$ & $<4$ & $<4$ & $<4$ & $<4$ & $<4$ & $<4$ \\
\hline & & 128 & $<4$ & $<4$ & $<4$ & $<4$ & $<4$ & $<4$ & $<4$ & $<4$ \\
\hline & & 128 & $<4$ & $<4$ & $<4$ & $<4$ & $<4$ & $<4$ & $<4$ & $<4$ \\
\hline 3rd passage & & & 128 & 32 & 256 & $<4$ & $<4$ & $<4$ & $<4$ & $<4$ \\
\hline \multirow[t]{4}{*}{$(n=5)$} & & & 64 & 32 & 64 & $<4$ & $<4$ & $<4$ & $<4$ & $<4$ \\
\hline & & & 128 & 64 & 1024 & $<4$ & $<4$ & $<4$ & $<4$ & $<4$ \\
\hline & & & 128 & 8 & 2048 & $<4$ & 8 & $<4$ & $<4$ & $<4$ \\
\hline & & & 64 & 64 & 128 & $<4$ & $<4$ & $<4$ & $<4$ & $<4$ \\
\hline
\end{tabular}

The possibility of ECEs preselection for pooling samples could eventually increase the isolation rate if the virus is present in samples at a very low concentration. In this study we used rtRT PCR detection of EIV in combination with consecutive passages of CAM homogenates. Influenza virus could infect the layer of susceptible cells covering CAM. Chorioallantoic membranes function as the respiratory organs of the embryo and as reported previously are probably the most abundant source of virus in eggs [11]. Our rtRT PCR test results showed a higher level of EIV genetic material in CAM than in AF. Influenza virus is transmitted from cell to cell in cellfree form, after budding from the cell surface, which is facilitated by neuraminidase activity. Progeny virions might also pass on to adjacent, uninfected cells when they remain associated with the parental cell surface [12]. Another mode of cell to cell transmission is direct translocation of viral ribonucleoprotein complexes via intercellular connections and infection of neighboring cells [13]. This might explain, why genetic material of influenza virus is detected in CAM while AF from the same ECE is negative. Other components of ECEs than AF were used by Tang et al. [14] in influenza virus isolation. The authors showed that passaging of mixed chick embryo and $\mathrm{AF}$ improved the isolation rate of avian influenza virus from field samples under non-optimal conditions (old fecal samples). CAM fragments maintained in roller tubes were used by Samuel et al. in 1981 for respiratory virus isolation and multiplication [15]. They used haemagglutination assay for confirmation of influenza A and B virus multiplication in in vitro CAM cultures inoculated with human clinical material. We used rtRT PCR as a highly sensitive detection method to confirm EIV multiplication in CAM.

In summary, we suppose that the monitoring of CAM homogenates from inoculated ECEs by rtRT PCR and their subsequent passages could possibly facilitate the isolation of EIV. Further experiments using more strains and clinical material are needed. The presented approach was used for equine influenza virus however, it probably could be used for influenza A viruses from other hosts.

\section{Additional files}

Additional file 1: Real time RT PCR for beta actin gene in AF and CAM of embryos inoculated with A/equine/Pulawy/2008. (XLSX 35 kb)

Additional file 2: Real time RT PCR for $M$ and beta actin genes in three consecutive passages of AF and CAM. (XLSX $183 \mathrm{~kb}$ )

\section{Abbreviations}

AF: Amniotic/allantoic fluids; CAM: Chorioallantoic membranes; Ct: Cycle threshold; ECEs: Embryonated chicken eggs; EID50: 50\% Egg Infective Dose; EIV: Equine influenza virus; HA: Haemagglutination assay; OIE: World Organisation for Animal Health; rtRT PCR: Real-time Reverse Transcription Polymerase Chain Reaction; SD: Standard Deviation

\section{Funding}

The study was supported by the project, KNOW (Leading National Research Centre).

Scientific Consortium "Healthy Animal - Safe Food", a decision of the Ministry of Science and Higher Education, No. 05-1/KNOW2/2015 (K/02/1.0).

\section{Availability of data and materials}

All relevant information is provided in this current manuscript.

\section{Authors' contributions}

IMG, MK, WR designed the experiments. IMG and MK performed experiments. IMG, MK, JFZ and WR analyzed the data and wrote/edited the manuscript. All authors read and approved the final manuscript. 


\section{Competing interests}

The authors declare that they have no competing interests.

\section{Consent for publication}

Not applicable.

Ethics approval and consent to participate

Not applicable.

\section{Publisher's Note}

Springer Nature remains neutral with regard to jurisdictional claims in published maps and institutional affiliations.

Received: 1 December 2016 Accepted: 16 June 2017

Published online: 21 June 2017

\section{References}

1. Slater J, Borchers K, Chambers T, Cullinane A, Duggan V, Elton D, et al. Report of the international equine influenza roundtable expert meeting at le Touquet, Normandy, February 2013. Equine Vet J. 2014;46:645-50.

2. Galvin P, Gildea S, Nelly M, Quinlivan M, Arkins S, Walsh C, et al. The evaluation of three diagnostic tests for the detection of equine influenza nucleoprotein in nasal swabs. Influenza Other Respir Viruses. 2014;8:376-83.

3. Oxburgh L, Hagström A. A PCR based method for the identification of equine influenza virus from clinical samples. Vet Microbiol. 1999;67:161-74.

4. Lu Z, Chambers TM, Boliar S, Branscum AJ, Sturgill TL, Timoney PJ, et al. Development and evaluation of one-step TaqMan real-time reverse transcription-PCR assays targeting nucleoprotein, matrix, and hemagglutinin genes of equine influenza virus. J Clin Microbiol. 2009;47:3907-13.

5. Quinlivan M, Dempsey E, Ryan F, Arkins S, Cullinane A. Real-time reverse transcription PCR for detection and quantitative analysis of equine influenza virus. J Clin Microbiol. 2005;43:5055-7.

6. Quinlivan M, Cullinane A, Nelly M, Van Maanen K, Heldens J, Arkins S. Comparison of sensitivities of virus isolation, antigen detection, and nucleic acid amplification for detection of equine influenza virus. J Clin Microbiol. 2004;42:759-63.

7. OIE (Office Internationale des Epizooties) 2015. Equine Influenza. In: Manual for Diagnostic Tests and Vaccines for Terrestrial Animals. Accessed Paris 2015: http://www.oie.int/fileadmin/Home/eng/Health_standards/tahm/2.05. 07_EQ_INF.pdf

8. Chomczynski P, Sacchi N. Single-step method of RNA isolation by acid guanidinium thiocyanate-phenol-chloroform extraction. Anal Biochem 1987;162:156-9.

9. World Health Organization (WHO), 2013. Real-time RT PCR Protocol for the Detection of Avian Influenza A (H7N9) Virus. Accessed 8 Apr 2013: http:// www.who.int/influenza/gisrs_laboratory/cnic_realtime_rt_pcr_protocol_a_ h7n9.pdf

10. Mann HB, Whitney DR. On a test of whether one of two random variables is stochastically larger than the other. Ann Math Statistics. 1947;18:50-60.

11. Hardy CT, Young SA, Webster RG, Naeve CW, Owens RJ. Egg fluids and cells of the chorioallantoic membrane of embryonated chicken eggs can select different variants of influenza a (H3N2) viruses. Virology. 1995;211:302-6.

12. Mori K, Haruyama T, Nagata K. Tamiflu-resistant but HA-mediated cell-to-cel transmission through apical membranes of cell-associated influenza viruses. PLoS One. 2011;6:e28178

13. Roberts $\mathrm{KL}$, Manicassamy B, Lamb RA. Influenza a virus uses intercellular connections to spread to neighboring cells. J Virol. 2015;89:1537-49.

14. Tang S, Li Y, Xia H, Huang J, Zhang Z, Zhu N, et al. Improved methods for isolation of avian influenza virus. J Virol Methods. 2014;210:22-5.

15. Samuel I, Mihail A, Teodosiu O, Barnaure F, Coban E, Petrescu A, et al. Comparative results of respiratory virus isolation attempts in chorioallantoic membrane fragments and embryonated chicken eggs. Virologie. 1981:32:297-303

\section{Submit your next manuscript to BioMed Central and we will help you at every step:}

- We accept pre-submission inquiries

- Our selector tool helps you to find the most relevant journal

- We provide round the clock customer support

- Convenient online submission

- Thorough peer review

- Inclusion in PubMed and all major indexing services

- Maximum visibility for your research

Submit your manuscript at www.biomedcentral.com/submit 